\title{
Influência do exercício físico sobre sódio e potássio séricos em equinos da raça Quarto de Milha e mestiços submetidos à prova de laço em dupla
}

\section{Influence of physical exercise on serum electrolytes in Quarter horses submitted to team roping}

\author{
Clarisse Simões Coelho, ${ }^{*}$ Priscila Faria Rosa Lopes, ${ }^{* *}$ Gabriela Lanschi Pissinati, ${ }^{* *}$ Larize de Oliveira Ramalho, ${ }^{* * * *}$ \\ Vinicius Ricardo Cuña de Souza*
}

\begin{abstract}
Resumo
O presente trabalho teve por objetivo avaliar a influência do exercício físico de alta intensidade e curta duração (provas de laço em dupla) sobre as concentrações séricas de sódio e potássio em equinos durante competição realizada no estado do Espírito Santo. Para tal, foram utilizadas amostras de soro de 20 equinos da raça Quarto de Milha e mestiços, avaliados nos momentos repouso (uma semana antes da prova, com o animal já em treinamento (T0), antes da prova atlética (T1) e imediatamente após o término da mesma (T2). Na avaliação de sódio sérico, os resultados registrados nos momentos T0, T1 e T2 foram, respectivamente, $141,3 \pm 7,0 \mathrm{mEq} / \mathrm{L}, 154,5 \pm 11,2 \mathrm{mEq} / \mathrm{L}$ e 139,4 $\pm 3,3 \mathrm{mEq} / \mathrm{L}$. Para o potássio sérico, os valores registrados nos momentos T0, T1 e T2 foram, respectivamente, $3,9 \pm 0,6 \mathrm{mEq} / \mathrm{L}, 4,4 \pm 0,8 \mathrm{mEq} / \mathrm{L}$ e 4,6 $\pm 0,4 \mathrm{mEq} / \mathrm{L}$. A análise dos resultados demonstrou que o exercício físico imposto não influenciou de forma significativa os valores encontrados de sódio, porém houve aumento significativo para o potássio sérico. Foi possível também destacar a influência do transporte sobre ambos os eletrólitos estudados.
\end{abstract}

Palavras-chave: equino, sódio, potássio, Quarto de Milha, laço em dupla.

\begin{abstract}
The aim of the present study was to evaluate the effects of high intensity and short duration physical exercise (roping team competition) on serum concentrations of sodium and potassium in horses during competition at Espírito Santo state, Brazil. Blood samples were taken from 20 Quarter Horses and cross-bred evaluated in three moments: at rest, one week before the competition, with the animals being trained (T0), just before the competition (T1), and immediately after the exercise (T2). Serum concentrations of sodium were $141.3 \pm 7.0 \mathrm{mEq} / \mathrm{L}, 154.5 \pm 11.2 \mathrm{mEq} / \mathrm{L}$ and $139.4 \pm 3.3 \mathrm{mEq} / \mathrm{L}$, respectively, on the moments T0, T1 and T2. Serum concentrations of potassium were $3.9 \pm 0.6 \mathrm{mEq} / \mathrm{L}, 4.4 \pm 0.8 \mathrm{mEq} / \mathrm{L}$ and $4.6 \pm 0.4 \mathrm{mEq} / \mathrm{L}$ respectively, on the moments T0, T1 and T2. Results showed that the imposed physical exercise did not influence serum concentrations of sodium, but leaded to a significant elevation of serum potassium. It was also possible observe the influence of transportation on both eletrolytes.
\end{abstract}

Keywords: equine, sodium, potassium, Quarter horse, team roping.

\section{Introdução}

Os animais da raça Quarto de Milha são os mais usados para as chamadas provas tipo western que incluem apartação, cinco tambores, laço de bezerro, laço em dupla, rédeas, maneabilidade, três tambores, western pleasure, vaquejada e laço comprido, onde a maioria dos circuitos é oficializada pela Associação Brasileira de Quarto de Milha ( $A B Q M)$, por ser um animal que se caracteriza principalmente pela força e docilidade, conseguindo partidas rápidas, paradas bruscas, grande capacidade de mudar de direção e enorme habilidade de girar sobre seu próprio eixo.

É sabido que o exercício físico realizado durante treinamentos ou competições gera em humanos e animais variações em diversos parâmetros fisiológicos (Kienzle et al., 2006) e a compreensão de tais mecanismos fisiológicos e sua caracterização são de enorme importância na avaliação da performance destes animais (Marques, 2002).

\footnotetext{
* Professor de Graduação em Medicina Veterinária e do Curso de Mestrado em Ciência Animal * Centro Universitário Vila Velha (UVV). Rua Comissário José Dantas de Melo, 21, Vila Velha - ES. CEP 29102-770. A quem enviar correspondência: e-mail: clarisse.coelho@uvv.br

** Residente Clínica, Cirurgia e Anestesiologia de Equinos - Centro Universitário Vila Velha (UVV).

*** Residente Laboratório Clínico Veterinário - Centro Universitário Vila Velha (UVV).

${ }^{* * * *}$ Mestranda - Programa de Mestrado em Ciência Animal - Centro Universitário Vila Velha (UVV).
} 
A depleção de fluidos corporais e das reservas de eletrólitos, em consequência principalmente da sudorese, representa uma limitação importante para a manutenção da performance durante exercícios de longa duração (Schott e Hinchcliff, 1998). As funções dos eletrólitos no organismo animal são múltiplas, já que não existe praticamente nenhum processo metabólico que seja independente ou mantenha-se inalterado diante de variações na concentração de eletrólitos (Fan et al., 1994).

Nas células, eles desempenham funções básicas, tais como a condução nervosa e a despolarização de fibras musculares, tornando possível a contração muscular. Ainda não está bem elucidado até quando essas funções podem ser prejudicadas pelo déficit de eletrólitos induzido pela atividade física. Grandes reduções hidroeletrolíticas durante o exercício estão relacionadas com o desenvolvimento da síndrome de exaustão e outros distúrbios metabólicos, como o flutter diafragmático sincrônico (Hinton, 1978).

O sódio é o principal cátion do plasma e do fluido intersticial ou extracelular, exercendo um papel muito importante na distribuição hídrica e na manutenção da pressão osmótica; já o potássio, configura o principal cátion intracelular, fundamental para a função muscular normal, respiração, função cardíaca, transmissão de impulsos nervosos e metabolismo de carboidratos (Hays e Swenson, 1996). O potássio, devido à sua localização intracelular, está relacionado intimamente com a estrutura e função celular e as alterações nos seus níveis séricos resultam em sinais de fadiga muscular e arritmias cardíacas (Hays e Swenson, 1996). Portanto, o pleno conhecimento da influência do exercício físico sobre o equilíbrio eletrolítico, principalmente de eletrólitos como sódio e potássio, é fundamental para o estabelecimento de uma terapia de reposição adequada, visando a melhora tanto da performance atlética como para promover uma rápida recuperação do animal.

Dentro da fisiologia do exercício equina existem diversos trabalhos na literatura envolvendo, principalmente, os parâmetros que permitem a avaliação da performance de cavalos de corrida e de enduro. Entretanto, poucos são os experimentos realizados com cavalos criados e treinados em condições tropicais e utilizados em provas do tipo western, como o laço em dupla. Segundo Hyppä e Pösö (1998), exercícios de alta intensidade e curta duração têm grande impacto no equilíbrio ácido-básico e, consequentemente, na regulação hidroeletrolítica.

Visando contribuir com as informações encontradas na literatura e facilitar o uso destas ferramentas diagnósticas no treinamento de equinos da raça Quarto de Milha, e mestiços, criados em condições tropicais, o objetivo do presente trabalho foi avaliar a influência do exercício físico de alta intensidade e curta duração (provas de laço em dupla) sobre as concentrações séricas de sódio e potássio durante competição realizada no estado do Espírito Santo.

\section{Material e métodos}

Foram utilizados vinte equinos da raça Quarto de Milha e seus mestiços (meio-sangue), sendo 18 machos e duas fêmeas, com peso médio de $500 \mathrm{~kg}$ e idade média de $9 \pm 4$ anos, considerados clinicamente hígidos. Estes animais pertencem a criatórios localizados na região da grande Vitória, estado do Espírito Santo. Os equinos pesquisados foram submetidos ao mesmo tipo de manejo alimentar e sanitário e encontravam-se no mesmo estágio de treinamento, executando as provas de laço em dupla há pelo menos dois anos. O transporte para o local da competição foi realizado no mesmo dia da competição, com grande parte dos animais chegando momentos antes da prova.

A prova de laço em dupla, também conhecida por team ropping, é uma atividade onde uma dupla de cavaleiros laça um bezerro, um responsável em laçar a cabeça (cabeceiro) e outro responsável em laçar os pés (peseiro). O tempo da prova, em média de oito a dez segundos, cronometrado desde o momento em que os laçadores saem do boxe até o momento em que o bezerro está laçado, com a corda esticada e amarrada à sela do cavalo. Tal atividade física caracteriza um exercício de alta intensidade e curta duração.

As amostras de sangue foram obtidas, de cada animal, em três momentos diferentes, assim caracterizados: momento repouso - T0 (obtida uma semana antes da prova atlética, com o animal em repouso, mas dentro do período de treinamento, no horário entre $8 \mathrm{~h}$ e $10 \mathrm{~h}$ da manhã), momento pré-prova - T1 (obtida antes da prova atlética) e momento pós-prova - T2 (obtida num período de até no máximo cinco minutos após a realização da atividade física). Para todos os animais usados, a amostra de sangue pós-prova foi coletada após a realização da primeira bateria completa de atividade, de forma a padronizar as coletas e avaliações. As condições de tempo (temperatura e umidade), bem como as características da pista, foram registradas.

As amostras de sangue foram obtidas, após antissepsia local, por meio de venopunção da jugular com agulhas descartáveis $(25 \mathrm{~mm} \times 0,8 \mathrm{~mm})$, com sistema a vácuo, ${ }^{1} \mathrm{em}$ tubos de vidro siliconizados sem anticoagulante, com capacidade para $9 \mathrm{ml}$, para as determinações séricas de sódio e potássio. Todas as amostras foram transportadas ao Laboratório Clínico Veterinário do Centro Universitário Vila Velha (UVV), onde foram imediatamente centrifugadas durante dez minutos a $2000 \mathrm{~g}^{2}$ para separação do soro e posterior mensuração.

O sódio e potássio séricos foram quantificados conforme recomendado por Korzun e Miller (1987), com uso de fotômetro de chama, ${ }^{3}$ em comprimento de onda específico, de $589 \mathrm{~nm}$ para a determinação do sódio e $768 \mathrm{~nm}$ para o potássio, na região de luz visível.

A interpretação dos resultados foi realizada por meio do programa estatístico computadorizado GraphPad InStat (versão 3.0). Devido à distribuição gaussiana dos dados, os mesmos foram avaliados através de testes paramétricos (análise de variância - ANOVA) para comparação entre médias com nível de significância de $5 \%$. Nestas análises, levou-se em consideração a influência do exercício físico nos níveis de sódio e potássio séricos.

\footnotetext{
1 Vacutainer

${ }^{2}$ Centrífuga modelo TDL80-2B - Marca Centribio

${ }^{3}$ Fotômetro de Chama modelo FC289 Marca Celm / Diluidor DA200
} 


\section{Resultados e discussão}

Os registros das condições meteorológicas no dia da prova, obtidos junto a jornais do dia, revelaram temperatura ambiente média de $29^{\circ} \mathrm{C}$ e umidade relativa do ar de $80 \%$, típicos de região tropical. A pista de areia encontrava-se seca.

$\mathrm{Na}$ Tabela 1 estão apresentados os valores médios e desvios-padrão para os valores séricos de sódio e potássio, bem como os valores de $p$ obtidos na análise de variância (ANOVA).

Tabela 1: Valores médios e desvios-padrão das concentrações séricas de sódio e potássio nos equinos da raça Quarto de Milha usados em prova de laço em dupla nos momentos repouso - T0 (uma semana antes da atividade atlética, em treinamento), antes (T1) e imediatamente após a realização da prova atlética (T2).

\begin{tabular}{lcccc}
\hline & Repouso & $\begin{array}{c}\text { Antes da } \\
\text { atividade atlética }\end{array}$ & $\begin{array}{c}\text { Logo após a } \\
\text { atividade } \\
\text { atlética }\end{array}$ & $P$ \\
\hline Frequência cardíaca & $41 \pm 5^{\mathrm{a}^{*}}$ & $42 \pm 9^{\mathrm{a}}$ & $89 \pm 16^{\mathrm{b}}$ & $<0,0001$ \\
\hline Sódio $(\mathrm{mEq} / \mathrm{l})$ & $141,3 \pm 7,0^{\mathrm{a}^{*}}$ & $154,5 \pm 11,2^{\mathrm{b}}$ & $139,4 \pm 3,3^{\mathrm{a}}$ & $<0,0001$ \\
\hline Potássio $(\mathrm{mEq} / \mathrm{l})$ & $3,9 \pm 0,6^{\mathrm{a}}$ & $4,4 \pm 0,8^{\mathrm{b}}$ & $4,6 \pm 0,4^{\mathrm{b}}$ & 0,0024 \\
\hline
\end{tabular}

* Letras minúsculas diferentes na mesma linha denotam diferença estatística significativa entre as médias $(p<0,05)$ obtido pelo teste ANOVA.

$\mathrm{Na}$ avaliação do sódio sérico foi possível observar que, com exceção do valor médio registrado no momento antes da atividade atlética ( $\mathrm{Tab}$ ), todos os demais encontram-se dentro dos valores de referência de 132-146 mEq/L estipulado por Kaneko (1997).

Apesar da redução significativa dos valores registrados após a prova em comparação com os obtidos antes da prova, não houve diferença significativa em relação ao momento repouso, o que nos permite afirmar que a redução provavelmente não ocorreu em consequência do exercício. Uma possível justificativa para a elevação significativa dos valores registrada no momento antes do exercício físico é o transporte dos animais para o local da prova, período no qual existe restrição ao acesso a água. Segundo Santos (2006), uma elevação na concentração sérica de sódio sempre indica um déficit de água em relação à quantidade de solutos corporais. Essa elevação pode ser em consequência da saída desse eletrólito do interior das células ou uma redução proporcional na taxa de excreção de sódio pela urina e suor.

Trabalhando também com exercício de curta duração e alta intensidade, Allen et al. (1984) e Gêiser et al. (1994) encontraram resultados diferentes frente a presente pesquisa com valores elevados de sódio no pós-exercício, justificado pelo desvio para o compartimento extracelular. Estes achados foram semelhantes aos descritos por Carlson (1995) e Cohen et al. (1993), que também observaram marcante aumento no sódio durante exercício máximo, refletindo as trocas no equilíbrio hídrico. A diferença para a presente pesquisa pode ter ocorrido pela menor perda corpórea de solutos em consequência de um exercício menos extenuante, visto que foi somente após uma primeira bateria de atividades.
A diminuição do sódio geralmente é observada em provas de resistência em decorrência da perda deste elemento pela sudorese, já que o suor dos equinos apresenta consideráveis quantidades de sódio, cloro e potássio e menores de cálcio e magnésio (Lucke e Heu, 1978; Rose et al. 1980; Titto et al., 2009). Carlson et al. (1976) e Rose et al. (1983) comprovaram tal afirmativa ao encontrarem níveis de sódio pós prova abaixo dos valores de referência em equinos de enduro.

Entretanto, Fernandes e Larsson (2000) observaram aumento do sódio sérico nos equinos da raça Árabe usados nas provas de enduro, fato justificado por Leaf (1962), que afirmou que a elevação dos níveis de sódio sérico seria indicativa da diminuição de fluido extracelular. Em trabalho mais recente, Martins et al. (2005) não encontraram alterações no sódio em até seis horas após o término do enduro. Supõe-se que estes animais tiveram acesso a água, minimizando as alterações eletrolíticas esperadas.

$\mathrm{Na}$ avaliação do potássio sérico foi possível observar aumento significativo dos valores registrados antes e após a prova quando comparado com os valores registrados no momento repouso (Tab). Todos os valores encontram-se dentro do intervalo de referência descrito por Kaneko (1997), entre 2,4 e 4,7 mEq/L. O aumento não esperado antes da prova para o potássio sérico, em comparação com o repouso, provavelmente ocorreu pelo mesmo motivo supracitado para o sódio sérico, em função do transporte dos animais para o local da prova, período no qual existe restrição ao acesso à água.

Art e Lekeux (2005) afirmam que a concentração do potássio estaria diretamente relacionada com a intensidade do exercício. Quanto maior a intensidade, maior o número de fibras musculares liberando potássio para o meio extracelular, o que pode justificar a ausência de um decréscimo importante desse eletrólito no soro ou no plasma decorrente da perda pelo suor (Snow et al., 1982; Harris e Snow, 1992; Art e Lekeux, 2005). Semelhantemente ao que também foi descrito por Cohen et al. (1993), que não encontraram alteração nos valores de potássio sérico após o exercício de intensidade máxima.

Entretanto, Harris e Snow (1992), trabalhando com equinos submetidos a exercício de intensidade moderada, encontraram aumento contínuo na concentração do potássio, com retorno aos valores da fase de aquecimento imediatamente após o exercício. Gêiser et al. (1994) e Carlson (1995) também observaram pequenas alterações na concentração sérica do potássio, em exercício de intensidade máxima. Este aumento de potássio após o exercício pode ser atribuído à perda de líquidos decorrente do desvio do compartimento vascular (Rose et al., 1983; Geiser, 1994) ou devido ao aumento da permeabilidade das células musculares ou à liberação do potássio eritrocítico (Agüera Buendia et al., 1994). Tais achados são semelhantes ao encontrado na presente pesquisa onde o valor médio registrado após a prova foi significativamente 
superior ao registrado no momento repouso, sugerindo a influência positiva do tipo de exercício imposto sobre a concentração deste eletrólito.

Outros trabalhos que estudaram exercícios de baixa intensidade e longa duração destacam a hipocalemia, porém em sua maioria foram observados em equinos realizando provas de resistência. Fernandes e Larsson (2000) descreveram a redução dos seus valores em todos os grupos de equinos avaliados durante provas de enduro atribuindo o fato à perda pelo suor, semelhante à descrição de Di Filippo et al. (2009), que relataram redução nos valores séricos de sódio e potássio após prova de enduro, Martins et al. (2008) justificaram a hipocalemia pós-

\section{Referências}

AGUERA BUENDIA, E.I.; RUBIO SUQUE, M.D.; AGUERA CARMONA, S.; ESCRIBANA DURÓN, B.M.; CASTEJÓN MONTIJANO, F. Efecto de una prueba de ejercício de intensidad creciente en parámetros bioquímicos sanguinos de potros pura raza española sin entrenamiento. Arch. Zootec. v. 43, p. 153-164, 1994.

ALLEN, B.V.; KANE, C.E.; POWELL, D.G.; Leucocyte counts in the healthy English thourogbred in training. Equine Veterinary Journal, v. 16, n. 3, p. 207-209, 1984.

ART, T.; LEKEUX, P. Execise-induced physiological adjustments to stressful conditions in sports horses. Livest. Prod. Scie., v. 92, p. 101-111, 2005.

CARLSON, G.P.; OCEN, P.O.; HARROLD, D. Clinic-pathologic alterations in normal and exhausted endurance horses. Theriogenology, v. 6, n. 2-3, 1976.

CARLSON, G.P. Interrelationships between fuid, electrolyte and acidbase balanc during maximal exercise. Equine Veterinary Journal, v. 18, p. 261-265, 1995.

COHEN, N.D.; ROUSSEL, A.J.; LUMSDEN, J.; COHEN, C.; GRIFT, E.; LEWIS, C. Alterations of fluid and electrolyte balance in thourogbred racehorses following strenuous exercise during training. J. Vet. Res. v. 57, p. $9-13,1993$.

DIFILIPPO, P.A.;GOMIDE, L.M.W.;OROZCO, C.A.G.; SILVA, M.A.G.da.; MARTINS, C.B.; NETO, J.C.DE.L.; SANTANA, A.E. alterações hemogasométricas e eletrolíticas de cavalos da raça árabe durante prova de enduro de 60 km. Ciência Animal Brasileira, v. 10, n. 3, p. 840-846, 2009.

FAN, L.C.R.; LOPES, S.T.A.; COSTA, P.R.S.; KRAUSE, A.; DUTRA, V.; CARVALHO, C.B. Anion gap no sangue venoso em equinos. Ciência Rural, v.24, p.101-104, 1994.

FERNANDES, W.R.; LARSSON, M.H.M.A. Alterações nas concentrações séricas de glicose, sódio, potássio, uréia e creatinina, em equinos submetidos a provas de enduro de $30 \mathrm{~km}$ com velocidade controlada. Ciência Rural, v. 30, n. 3, p. 393-398, 2000.

FERRAZ, G. C. Respostas endócrinas, metabólicas, cardíacas e hematológicas de equinos submetidos ao exercício intenso e à administração de cafeína, aminofilina e clembuterol. 2006. 98 f. Tese (Doutorado) - Faculdade de Ciências Agrárias e Veterinárias Universidade Estadual Paulista "Julio de Mesquita Filho", Jaboticabal, 2006.

GEISER, D.R.; ANDREWS, F.; SOMMERDAHL, C.;WHITE, S.; MAYKUTH, P.; YOUNGER, M.S. Electrolyte and acid-base changes in combined training horses after the cross-country event. Equine Practice, v. 16, n. 7, p. 20-25, 1994.

HARRIS, P.; SNOW, D.H. Plasma potassium and lactated concentrations in thoroughbred horses doing exercise of varying intensity. Equine Veterinary Journal. v. 23, n. 3, p. 220-225, 1992. exercício como consequência de reabsorção renal de sódio às custas da excreção de potássio e íons hidrogênio.

\section{Conclusões}

Os resultados do presente estudo nos permitiram concluir que o tipo de exercício físico imposto levou a uma elevação significativa nas concentrações séricas de potássio, porém sem influenciar nos valores séricos de sódio. Além disto, foi possível concluir que o transporte também influenciou as concentrações séricas dos referidos eletrólitos em consequência da privação de água.

HAYS, V.W.; SWENSON, M.J. Ossos e Minerais. In: SWENSON, M.J. Dukes: Fisiologia dos animais domésticos. Rio de Janeiro: Guanabara-Koogan, 1996. Cap. 29, p. 471-487.

HINTON, M. The biochemical and clinical of exhaustion in the horse. Vet. Annu., v. 18, p. 169-172, 1978.

HYPPÄ, S.; PÖSÖ, A.R. Fluid, electrolyte and acid-base responses to exercise in racehorses. Veterinary Clinics of North America: Equine Practice, v. 14, n. 1, p. 121-127, 1998.

KANEKO, J. J. Clinical biochemistry of domestic animals. 5. ed. San Diego: Academic Press, 1997.

KIENZLE. E.; FREISMUTH A.; REUSCH, A. Double blind placebo controlled vitamin $E$ and selenium supplementation of Sport horses with unspecified muscle problems. J. Nutr., v. 136, n. 7, p. 20452047, 2006.

LEAF, A. The clinical and physiologic significance of the serum sodium concentrations. New Eng. J. Med., v.267, p.24-30, 1962.

MARQUES, M. S. Influência do exercício físico sobre os níveis de lactato plasmático e cortisol sérico em cavalos de corrida. 2002, 70 f. Dissertação (Mestrado) - Faculdade de Medicina Veterinária e Zootecnia - Universidade de São Paulo. São Paulo, 2002.

MARTINS, C.B.;OROZCO, C.A.G.; D'ANGELIS, F.H.F.; FREITAS, E.V.V.; CHRISTOVÃO, F.G.; NETO, A.de.Q.; NETO, J.C.de.L. Determinação de variáveis bioquímicas em equinos antes e após a participação em prova de enduro. R. Bras. Ci. Vet., v. 12, n. 1/3, p. 62-65, 2008.

ROSE, J. R.; ARNOLD, K. S.; CHURCH, S. Plasma and sweat electrolyte concentrations in the horse during long distance exercise. Eq. Vet. J., v. 12, n. 1, p. 19-22, 1980.

ROSE, R.J.; ALLEN, J.R.; HODGSON, D.R.; STEWART, J.H. Responses to submaximal treadmill exercise and training in the horse: changes in haematology, arterial blood gas and acid base measurements, plasma biochemical values and heart rate. Veterinary Record, v. 113, p. 612618, 1983.

SANTOS, V.P. dos. Variações hemato-bioquimícas em equinos de salto submetidos a diferentes protocolos de exercício físico. 2006. 94 f. Tese (Mestrado) - Faculdade de Veterinária - Universidade Federal de Rio Grande do Sul, Porto Alegre, 2006.

SCHOTT II, H. C.; HINCHCLIFF, K. W. Treatments affecting fluid and electrolyte status during exercise. Vet. Clin. North Am. Equine Pract., v. 14, p. 175-204, 1998.

SNOW, D.H.; KERS, M.G.; NIMNO, H.A.; ABBOTT, E.M. Alterations in blood, sweat, urine and muscle composition during prolonged exercise in the horse. The Veterinary Record, v. 17, p. 377-384, 1982.

TITTO, E.A.L.; PEREIRA, A.M.F.; TOLEDO, L.R.de.A.; PASSINI, R.; FILHO, J.C.M.N.; GOBESSO, A.A.de.O.; ETCHICHURY, M.; TITTO, C.G. Concentração de eletrólitos em equinos submetidos a diferentes temperaturas. Rev. Bras. Saúde Prod. An., v. 10, n. 1, p. 236-244, 2009. 